\title{
ESVAZIAMENTO CERVICAL SELETIVO NO TRATAMENTO DO CARCINOMA EPIDERMÓIDE DO ANDAR INFERIOR DA BOCA
}

\author{
SQUAMOUS CELL CARCINOMA OF THE MOUTH. RATIONALE FOR SELECTIVE NECK \\ DISSECTION
}

\author{
Ali Amar' ${ }^{1}$; Sergio Altino Franzi ${ }^{1}$; Otávio Alberto Curioni, TCBC- SP'; \\ Marcos Brasilino de Carvalho ${ }^{1}$; Abrão Rapoport, ECBC-SP ${ }^{1}$
}

\begin{abstract}
RESUMO: Objetivo: O esvaziamento cervical seletivo, removendo apenas os linfonodos com maior probabilidade de metástases, pode ser adequado para o tratamento do pescoço nos carcinomas epidermóides do andar inferior da boca. O objetivo deste estudo é avaliar os níveis linfonodais acometidos por metástases em uma série de pacientes tratados em uma única instituição. Método: Foram avaliados os registros de 416 pacientes com câncer de lábio, língua oral, soalho de boca, gengiva inferior, região jugal e trígono retromolar, submetidos à 519 esvaziamentos cervicais entre 1977 e 2001, quanto ao níveis linfonodais acometidos por metástases. Resultados: O nível I estava acometido em 107/519 (20\%) esvaziamentos, o nível II em 147/519 (28\%), o nível III em 75/519 (14\%), o nível IV em 32/419 (7\%) e o nível V em 22/419 (5\%). A taxa de falso-negativos e de falso-positivos foi de 36\% e 30\%, respectivamente. Os pacientes com metástases nos níveis I e/ou II, III, IV ou V tiveram uma média 2,2; 4,8; 6,5 e 7,5 linfonodos comprometidos, respectivamente ( $\mathrm{p}<0.0001)$. As metástases no nível IIb foram diagnosticadas em $21(5 \%)$ pacientes, sendo que $11(52 \%)$ deles tinham metástases no nível V ( $<<0,0001)$. Conclusão: O esvaziamento cervical dos níveis I a IV remove quase todos os linfonodos com risco de metástases no carcinoma epidermóide do andar inferior da boca. O esvaziamento seletivo com esta extensão é adequado para o tratamento eletivo do pescoço (N0), onde ocorrem aproximadamente $30 \%$ de casos falso-negativos, e também pode ser suficiente no esvaziamento terapêutico $(\mathrm{N}+)$. Quando ocorrem metástases no nível IIb, aumenta significativamente o risco de metástases no nível V (Rev. Col. Bras. Cir. 2005; 32(6): 321-324).
\end{abstract}

Descritores: Metástase linfática; Esvaziamento cervical; Carcinoma de células escamosas; Neoplasias bucais.

\section{INTRODUÇÃO}

O esvaziamento eletivo do pescoço é indicado quando o risco de metástases ocultas é de aproximadamente $20 \%$ ou maior, devido ao pior prognóstico relacionado à recidiva cervical, quando até $50 \%$ dos pacientes são inoperáveis por ocasião do diagnóstico ${ }^{1}$. A probabilidade de metástases ocultas e os níveis linfonodais habitualmente comprometidos estão bem definidos para os tumores primários dos diferentes sítios anatômicos das vias aerodigestivas superiores, permitindo o planejamento terapêutico a partir do estadiamento clínico da doença ${ }^{2-4}$.

No pescoço N0, quando indicado o esvaziamento cervical, se preconiza a realização de um esvaziamento seletivo, removendo apenas as cadeias linfáticas com maior probabilidade de comprometimento. O tratamento do pescoço com metástases é o esvaziamento radical, contemplando as possíveis modificações relacionadas à preservação das estruturas não-linfáticas. Considerando que aproximadamente 30\% dos pacientes sem linfonodos clinicamente suspeitos apresentam metástases no exame histológico, geralmente não identificadas no intra-operatório, o potencial terapêutico dos esvaziamentos seletivos adquire relevância ${ }^{5,6}$. Como a maioria das recidivas cervicais nos pacientes submetidos ao esvaziamento seletivo ocorrem dentro do campo operatório, isto sugere que um tratamento menos radical no pescoço possa ser adotado também nos pacientes com metástases linfonodais ${ }^{1,7}$.

O objetivo deste estudo é avaliar a freqüência de metástases linfáticas nas diferentes cadeias linfonodais, considerando o planejamento terapêutico do pescoço nos carcinomas epidermóides da boca.

\section{MÉTODO}

Foram revisados os prontuários de 431 pacientes com carcinoma epidermóide do andar inferior da boca, submetidos à ressecção do tumor primário e esvaziamento cervical no Departamento de Cirurgia de Cabeça e Pescoço e Otorrinolaringologia do Hospital Heliópolis, Hosphel, entre dezembro de 1977 e dezembro de 2001. Os linfonodos foram classificados em nove níveis e reclassificados de acordo com a proposta da American Head and Neck Society ${ }^{8}$. Foi avaliada a incidência de metástases linfonodais nos diferentes níveis em relação ao estadiamento pré-operatório e os achados pósoperatórios.

Foram excluídos 15 pacientes cujas informações do exame histológico não foram recuperadas, restando 416 , sendo 366 masculinos e 50 femininos. A idade apresentou média de 54 anos, variando de 22 a 84 . O sítio primário foi a língua e/ ou soalho em 258 , área retromolar em 64 , gengiva inferior em

1. Cirurgião do Departamento de Cirurgia de Cabeça e Pescoço e Otorrinolaringologia do Hospital Heliópolis - HOSPHEL - SP.

Recebido em 16/08/2005

Aceito para publicação em 14/10/2005

Conflito de interesse : nenhum

Fonte de financiamento: nenhuma

Trabalho realizado no Departamento de Cirurgia de Cabeça e Pescoço e Otorrinolaringologia do Hospital Heliópolis, HOSPHEL, São Paulo. 
63, lábio em 24 e região jugal em sete pacientes. Os pacientes foram reestadiados conforme a classificação TNM de 2002, da Union International Contre Cancer e American Joint Committee on Cancer (UICC-AJCC). Quanto ao estadiamento do tumor primário, nove casos eram Tx, 16 T1, 137 T2, 125 T3 e 129 T4. Quanto ao estadiamento do pescoço, 204 eram N0 e 212 eram $\mathrm{N}+$. Foram realizados 103 esvaziamentos bilaterais e 313 unilaterais. Do total de 519 esvaziamentos, 419 foram radicais ou radicais modificados e 100 supra-omohioideos.

A análise estatística empregou o teste de Chi-quadrado e o teste de Kruskal-Wallis, considerando significativo $\mathrm{p}<0,05$.

\section{RESULTADOS}

O nível I estava comprometido em 107/519 (20\%), o nível II em 147/519 (28\%), o nível III em 75/519 (14\%), o nível IV em 32/419 (7,6\%) e o nível V em 23/419 (5,4\%) dos esvaziamentos (Figura 1).

Entre os 204 pacientes N0 foram diagnosticados 75 (36\%) falso-negativos e entre os $212 \mathrm{~N}+$ foram diagnosticados $64(30 \%)$ falso-positivos. Quando presentes, as metástases acometeram predominantemente o nível II (Tabela 1).

Nos 223 pacientes $\mathrm{pN}+$, a média de linfonodos comprometidos foi de 3,2 por paciente. Os pacientes com metástases no nível I e/ou II apresentavam média de 2,2 linfonodos comprometidos. Os pacientes com metástases nos níveis III, IV, e V apresentavam um número progressivamente maior de linfonodos comprometidos, com médias de 4,8; 6,5 e 7,5 respectivamente $(\mathrm{p}<0,0001)$.

As metástases no nível IIb foram diagnosticadas em 21 pacientes (5\%), sendo 7/204 (3,4\%) nos casos N0 e 14/212 $(6,6 \%)$ nos casos $\mathrm{N}+$. Dezessete destes pacientes $(80 \%)$ tinham metástases no nível IIa e $11(52 \%)$ apresentavam metástases também no nível V ( $\mathrm{p}<0,0001)$.

Quando confirmada histologicamente a presença de metástases nos níveis I, II ou III em pacientes N0, a incidência de metástases nos níveis IV e V foi 11/73 (15\%) e 7/73 (9\%), respectivamente. Nos casos $\mathrm{N}+$, a incidência nos níveis IV e V foi $17 / 146(11 \%)$ e $14 / 146(9 \%)$, respectivamente.

As metástases no nível III, na ausência de metástases nos níveis I e II, ocorreram em 15 pacientes. Três pacientes apresentaram metástases isoladas no nível IV e apenas um paciente no nível V.

Entre os pacientes pN+, 124 tinham metástases em apenas 1 nível e 99 apresentavam metástases em múltiplos níveis (Tabela 2).

\section{DISCUSSÃO}

Embora inicialmente considerado um procedimento de estadiamento, o potencial terapêutico do esvaziamento seletivo não pode ser menosprezado, uma vez que algumas metástases são identificadas apenas no exame histológico. Nesta situação, a irradiação pós-operatória proporciona taxas de controle cervical semelhantes aos esvaziamentos radicais, além do que, a maioria das recidivas ocorre dentro do campo esvaziado $^{1,7,9-11}$. Ao considerarmos o seu potencial terapêutico,

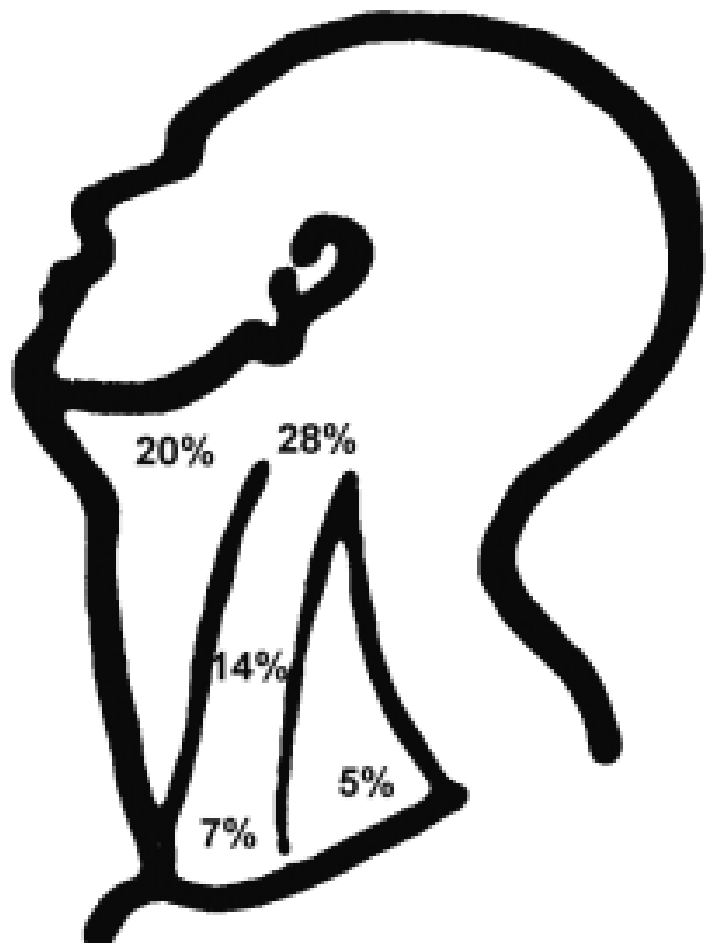

Figura 1 - Distribuição das metástases linfonodais.

uma importante questão é a necessidade de irradiação pósoperatória. Nos casos com apenas um ou dois linfonodos metastáticos, na ausência de ruptura capsular, o esvaziamento radical modificado é suficiente para o controle regional da doença. Assim, o benefício ao reduzir a extensão do esvaziamento pode ser anulada pela necessidade de radioterapia pósoperatória. Habitualmente administrada tanto no pescoço como no sítio primário, a irradiação pós-operatória não apresenta benefício terapêutico comprovado no controle da doença primária ressecada com margens adequadas, especialmente nos tumores menores do que $4 \mathrm{~cm}$ (T2) ${ }^{12}$. Os conceitos atuais não consideram que uma redução na extensão do esvaziamento cervical possa ser compensada pela radioterapia pós-operatória, mas quando ambas modalidades terapêuticas são empregadas, parece que o tratamento complementar pode ter sua extensão reduzida ${ }^{13}$.

O tipo de esvaziamento habitualmente empregado no tratamento eletivo do pescoço nos tumores da boca é o esvaziamento supra-omohioideo (níveis I, II e III), porém a

Tabela 1 - Metástases linfonodais em diferentes níveis de acordo com o estadiamento clínico do pescoço $(N)^{*}$.

\begin{tabular}{rcc}
\hline & N0 & N+ \\
& $\mathbf{n}(\boldsymbol{\%})$ & $\mathbf{n}(\boldsymbol{\%})$ \\
\hline I & $30 / 204(14)$ & $72 / 212(33)$ \\
II & $40 / 204(19)$ & $99 / 212(46)$ \\
III & $27 / 204(13)$ & $45 / 212(21)$ \\
IV & $12 / 204(5)$ & $19 / 212(8)$ \\
V & $8 / 204(3)$ & $14 / 212(6)$ \\
\hline
\end{tabular}

* somente 158 pacientes NO e 203 pacientes $N+$ submeteram-se ao esvaziamento radical. 
Tabela 2 - Número de níveis linfonodais com metástases de acordo com o estadiamento do pescoço $(N)$.

\begin{tabular}{lrrrr}
\hline Metástases & \multicolumn{2}{c}{ NopN+ } & \multicolumn{2}{c}{$\mathbf{N}+\mathbf{p N +}$} \\
\hline 1 nível & 45 & $(60)$ & 79 & $(53)$ \\
2 níveis & 20 & $(26)$ & 44 & $(29)$ \\
3 níveis & 8 & $(10)$ & 19 & $(12)$ \\
4 níveis & 2 & $(2)$ & 4 & $(2)$ \\
5 níveis & 0 & $(0)$ & 2 & $(1)$ \\
Total & $75(100)$ & $148(100)$ \\
\hline
\end{tabular}

possibilidade de skip metastase torna este procedimento inadequado em aproximadamente $5 \%$ a $10 \%$ dos $\operatorname{casos}^{14}$. Ao considerar uma skip metastase, não podem ser ignorados os estudos da drenagem linfática das vias aerodigestivas superiores $^{2,3}$. A ponta da língua e a região posterior do soalho da boca drenam para coletores linfáticos que se dirigem aos linfonodos júgulo-carotídeos próximos do músculo omohioideo (limite entre os níveis III e IV $)^{15}$. Assim, o nível IV deve ser rotineiramente esvaziado nos tumores desta localização. Não se espera um fluxo retrógrado das cadeias jugulares para as cadeias espinais, explicando a baixa probabilidade de metástases no nível $\mathrm{V}$, exceto quando os linfonodos juncionais estão comprometidos ${ }^{16}$. Os pacientes com metástases nos níveis IV e V habitualmente apresentam elevado número de linfonodos comprometidos em múltiplos níveis, sugerindo mais uma doença disseminada do que skip metastase. Diante do baixo risco de comprometimento dos níveis IV e $\mathrm{V}$ entre os pacientes com metástases em menos do que três linfonodos, parece adequado usar os mesmos critérios da radioterapia complementar aplicados nos esvaziamentos radicais. Embora sejam feitas inferências de que a radioterapia é efetiva na erradicação da doença subclínica no linfonodo, faltam estudos que confirmem esta hipótese. ${ }^{17}$ As evidências sugerem que a radioterapia isolada é insuficiente no tratamento das metástases cervicais estabelecidas $^{12}$.

Dois pontos controversos no tratamento eletivo do pescoço se referem à necessidade de remover o nível IIb e o nível IV. Quando detectados linfonodos comprometidos nos níveis I, II e/ou III, havia metástases no nível IV em 13\% dos pacientes, o que torna oportuno o seu esvaziamento. A inclusão do nível IV no esvaziamento supraomohioideo não acrescenta morbidade significativa e aumenta o tempo cirúrgico em poucos minutos. Linfonodos comprometidos no nível IIb foram diagnosticados em $5 \%$ dos pacientes, incidência similar ao relatado por Silverman et a $l^{18}$. A presença de metástases no nível IIb foi um bom indicador de doença no nível V, sendo que mais de $50 \%$ dos pacientes com metástases no nível IIb também apresentavam metástases no nível V. Entre os pacientes $\mathrm{N}+$, o nível $\mathrm{V}$ estava comprometido em $7 \%$ dos casos. Os resultados no presente estudo apontaram uma incidência maior de metástases no nível $\mathrm{V}$ em comparação ao relatado por outros autores ${ }^{1,19}$.

Ao reduzir a extensão do esvaziamento, deve ser considerada a possibilidade de recidiva e o resgate da mesma. A exclusão do nível IIb nas lesões da boca, com a justificativa de reduzir a morbidade causada pela manipulação do nervo aces- sório, é arriscada porque uma recidiva nesta localização pode ser de difícil resgate. A manipulação cuidadosa do nervo permite o esvaziamento da cadeia espinal alta com mínima seqüela. A exclusão do nível V pode ser segura, pois este nível tem pouca probabilidade de estar comprometido nos tumores da boca e uma eventual recidiva tem, do ponto de vista anatômico, boa probabilidade de resgate. $\mathrm{O}$ esvaziamento dos níveis I a IV permite preservar o plexo cervical, com mínima manipulação do nervo acessório e do músculo esternocleidomastoideo, com ótimo resultado estético e funcional.

A presença de metástases linfonodais está relacionada à piora significativa do prognóstico, porém não relacionada apenas ao controle cervical. O esvaziamento cervical, seguido ou não de radioterapia pós-operatória, é efetivo no controle regional da doença, mas estes pacientes apresentam maior taxa de recidiva local e metástases à distância também.

O percentual de pacientes com pescoço falso-positivo foi similar ao percentual de falso-negativos. Aproximadamente um terço dos pacientes submetidos a um esvaziamento radical poderiam ter se beneficiado de um procedimento menos agressivo sem prejuízo do controle da doença. Uma taxa maior de casos falso-positivos foi relatada com doença clinicamente limitada ao nível I, sugerindo que o esvaziamento seletivo possa ser indicado nesta situação ${ }^{1}$.

Considerando a drenagem linfática, ainda merece ser mencionada a possibilidade de metástases nos linfonodos linguais ou sublinguais. Estes linfonodos são encontrados junto à borda medial do músculo genio-hioideo (gordura meso-lingual) e junto à glândula sublingual (sobre o músculo milohioideo). Talvez algumas recidivas no sítio primário tenham origem nestes linfonodos, o que poderia explicar a maior incidência de recidiva local nas ressecções em di-bloco ${ }^{4,15,20}$.

A pesquisa do linfonodo sentinela ainda está em fase experimental na cabeça e pescoço. A identificação correta da primeira estação de drenagem exige treinamento específico e experiência do cirurgião ${ }^{21}$. Assim como o esvaziamento terapêutico tende a reduzir sua extensão, a proposta de esvaziamento eletivo deve naturalmente evoluir para a pesquisa do linfonodo sentinela, desde que seja confirmada a aplicabilidade deste conceito nos tumores das vias aerodigestivas superiores. Outro aspecto que favorece a pesquisa do linfonodo sentinela se relaciona ao possível efeito prejudicial da remoção dos linfonodos sobre a resposta imunológica, uma questão ainda não respondida ${ }^{22}$. Uma limitação do presente estudo se refere à possibilidade de micrometástases não detectadas no exame histológico rotineiro, porém o significado clínico destas micrometástases permanece incerto.

Mesmo na presença de metástases linfonodais, em casos selecionados, o esvaziamento dos níveis I a IV pode ser adequado no tratamento do carcinoma epidermóide do andar inferior da boca. A repercussão da redução do esvaziamento sobre o controle regional da doença deve ser avaliado em estudos especificamente desenhados, para definir quais pacientes podem se beneficiar com a redução da cirurgia bem como os critérios para a indicação de radioterapia pós-operatória. 


\begin{abstract}
Background: The indication of selective neck dissection with removal of lymph nodes at risk only, can be an adequate therapeutic approach for squamous cell carcinoma of the mouth. Our objective is to assess the level of neck node metastases in patients with squamous cell carcinoma of the lower part of mouth treated in a single institution. Methods: 416 patients with lip, oral tongue, floor of mouth, lower gingiva, buccal mucosa and retromolar trigone cancer underwent neck dissection from 1977 to 2001 and the level of metastases were assessed. Results: Level I was involved in 107/519(20\%) neck dissection, level II in 147/519 (28\%), level III in 75/519(14\%), level IV in 32/419(7\%) and level V in 22/419 (5\%). The false-negative rate was $36 \%$ and the false-positive was 30\%. Patients with level I and/or II, III, IV or V had an average of 2.2, 4.8, 6.5 and 7.5 positive lymph nodes respectively $(p<0.0001)$. Metastases at level IIb were diagnosed in $21(5 \%)$ patients, 11 (52\%) of them had metastases at level V $(p<0.0001)$. Conclusions: Neck dissection, including levels I to IV, remove almost all metastatic lymph nodes from squamous cell carcinoma of the mouth and can be an adequate therapeutic approach even when positive lymph nodes are detected. Metastasis at level IIb increased the risk of disease in level V.
\end{abstract}

Key words: Lymphatic metastasis; Neck dissection; Carcinoma, Squamous cell; Mouth neoplasms.

\section{REFERÊNCIAS}

1. Carvalho AL, Kowalski LP, Borges JA, et al. Ipsilateral neck cancer recurrences after elective supraomohyoid neck dissection. Arch Otolaryngol Head Neck Surg. 2000;126(3):410-2.

2. Lindberg R. Distribution of cervical lymph node metastases from squamous cell carcinoma of the upper respiratory and digestive tracts. Cancer. 1972;29(6):1446-9.

3. Shah JP, Candela FC, Poddar AK. The patterns of cervical lymph node metastases from squamous carcinoma of the oral cavity. Cancer. 1990;66(1):109-13.

4. Woolgar JA. Histological distribution of cervical lymph node metastases from intraoral/oropharyngeal squamous cell carcinomas. Br J Oral Maxillofac Surg. 1999;37(3):175-80.

5. Rassekh CH, Johnson JT, Myers EN. Accuracy of intraoperative staging of the NO neck in squamous cell carcinoma. Laryngoscope. 1995;105(12 Pt 1):1334-6.

6. Kaya S, Yilmaz T, Gürsel B, et al. The value of elective neck dissection in treatment of cancer of the tongue. Am J Otolaryngol. 2001;22(1):59-64.

7. Muzaffar K. Therapeutic selective neck dissection: a 25-year review. Laryngoscope. 2003;113(9):1460-5.

8. Robbins KT, Atkinson JL, Byers RM, et al. The use and misuse of neck dissection for head and neck cancer. J Am Coll Surg. 2001;193(1):91-102.

9. Kolli VR, Datta RV, Orner JB, et al. The role of supraomohyoid neck dissection in patients with positive nodes. Arch Otolaryngol Head Neck Surg. 2000; 126(3):413-6.

10. Chepeha DB, Hoff PT, Taylor RJ, et al. Selective neck dissection for the treatment of neck metastasis from squamous cell carcinoma of the head and neck. Laryngoscope. 2002; 112(3):434-8.

11. Andersen PE, Warren F, Spiro J, et al. Results of selective neck dissection in management of the node-positive neck. Arch Otolaryngol Head Neck Surg. 2002; 128(10):1180-4.

12. Magge KT, Myers EN, Johnson JT. Radiation following surgery for oral cancer: impact on local control. Laryngoscope. 2003; 113(6):933-5.
13. Stenson KM, Haraf DJ, Pelzer H, et al. The role of cervical lymphadenectomy after aggressive concomitant chemoradiotherapy: the feasibility of selective neck dissection. Arch Otolaryngol Head Neck Surg. 2000; 126(8):950-6.

14. Byers RM, Weber RS, Andrews T, et al. Frequency and therapeutic implications of "skip metastases" in the neck from squamous cell carcinoma of the oral tongue. Head Neck. 1997; 19(1):14-9.

15. Rouvière H. Anatomie des lymphatiques de l'homme. Paris: Masson; 1932.

16. Fisch UP, Sigel ME. Cervical lymphatic system as visualized by lymphography. Ann Otol Rhinol Laryngol. 1964;73:870-82.

17. Shasha D, Harrison LB. Elective irradiation of the NO neck in squamous cell carcinoma of the upper aerodigestive tract. Otolaryngol Clin North Am. 1998; 31(5):803-13.

18. Silverman DA, El-Hajj M, Strome S, et al. Prevalence of nodal metastases in the submuscular recess (level IIb) during selective neck dissection. Arch Otolaryngol Head Neck Surg. 2003;129(7):724-8.

19. Davidson BJ, Kulkarny V, Delacure MD, et al. Posterior triangle metastases of squamous cell carcinoma of the upper aerodigestive tract. Am J Surg. 1993; 166(4):395-8.

20. Ozeki S, Tashiro H, Okamoto M, et al. Metastasis to the lingual lymph node in carcinoma of the tongue. J Maxillofac Surg. 1985;13(6):277-81.

21. Alex JC. The application of sentinel node radiolocalization to solid tumors of the head and neck: a 10-year experience. Laryngoscope. 2004;114(1):2-19.

22. Heys SD, Eremin O. The relevance of tumor draining lymph nodes in cancer. Surg Gynecol Obstet. 1992;174(6):533-40.

Endereço para correspondência:

Abrão Rapoport

Rua Iramaia, $n^{\circ} 136$ - Jd. Europa

CEP-1450-020 - São Paulo -SP

E-mail: arapoport@terra.com.br 